\title{
PREVALÊNCIA DE DESORDENS TEMPOROMADIBULARES EM MÚSICOS
}

\author{
Maiara Moreira Barbosa ${ }^{1}$ \\ Raquel Santos Carvalho Cunha \\ Marilia Gabriela Lopes de Oliveira $^{3}$
}

\begin{abstract}
Resumo: A DTM (desordem temporomandibular) é um termo utilizado para reunir um grupo de doenças que acometem os músculos mastigatórios, articulação temporomandibular e estruturas adjacentes. Elas podem ser classificadas como sendo de origem articular ou muscular. Uma de suas causas pode ser proveniente da prática de um instrumento musical; sendo os músicos um grupo bastante suscetível ao desenvolvimento de uma disfunção. Tocar um instrumento musical de sopro pode ser considerado uma parafunção do sistema estomatognático; uma vez que exige uma atividade muscular superior à função fisiológica normal, sendo, por isso, um possivel fator desencadeante ou agravante de DTM. (LACERDA ET $A L$, 2015) O objetivo deste trabalho é determinar se há relação existente entre a prática de um instrumento musical e o desenvolvimento de DTM,Essa pesquisa será desenvolvida através de um questionário, com quatorze questões dissertativas e alternativas, cujas perguntas foram baseadas em artigos publicados anteriormente. E serão entregues a músicos de orquestras de igrejas da região para a análise de DTMs em músicos instrumentistas
\end{abstract}

Palavras-chave: Dtm; Desordem temporomandibular; Músicos.

\footnotetext{
1 Odontologia/UNIVAP, Brasil. E-mail: maiaramb2307@hotmail.com.

2 Odontologia/UNIVAP, Brasil. E-mail: kel.scarvalho@yahoo.com.br.

3 Odontologia/UNIVAP, Brasil. E-mail: mariliaorto@gmail.com.
} 